\title{
The role of the exposome in promoting resilience or susceptibility after SARS-CoV-2 infection
}

\author{
Sean X. Naughton $\mathbb{1}^{1} \cdot$ Urdhva Raval $^{1} \cdot$ Joyce M. Harary ${ }^{1} \cdot$ Giulio M. Pasinetti ${ }^{1,2}$
}

Received: 9 April 2020 / Revised: 22 April 2020 / Accepted: 28 April 2020 / Published online: 12 May 2020

(c) Springer Nature America, Inc. 2020

\section{To the Editor:}

One of the more perplexing aspects of the recent SARSCoV-2 pandemic is the high level of variability among patients in terms of disease severity. It is currently unclear why some patients remain largely asymptomatic, while others require intensive care. A key factor in determining variations in disease severity may be the exposome, or measure of all exposures across an individual's lifetime (environmental toxins, pharmacological treatments, lifestyle, diet, etc.) (Fig. 1). Sequence similarities between SARS-CoV-2, the infectious agent behind the Coronavirus Disease 2019 (COVID-19) pandemic, and other coronaviruses indicate that SARS-CoV-2 spike protein binds to human angiotensin converting enzyme 2 (ACE2) as the virus receptor for entry [1]. ACE2 belongs to the ACE family of dipeptidyl carboxydipeptidases and is expressed in epithelial cells of the lungs, intestine, kidney, brain, and blood vessels [1-3]. Given the ubiquitous distribution of ACE2 throughout the host, increases in ACE2 receptor expression may potentially result in the proliferation of SARS-CoV-2 to multiple organ systems.

Exposure to environmental toxins as well as lifestyle choices can affect ACE2 expression, and may possibly increase the severity of infection. For example, exposure to ultrafine particulate matter from air pollution (PM 2.5) has previously been shown to increase the expression of ACE2 [4]. In line with these findings, a recent report indicates that higher levels of air pollution may be a contributing factor to the increased fatality rate among

Giulio M. Pasinetti

giulio.pasinetti@mssm.edu

1 Department of Neurology, Mount Sinai School of Medicine, New York, NY 10029, USA

2 James J. Peters Veterans Affairs Medical Center, Bronx, NY 10468, USA
COVID-19 patients in northern Italy [5]. Dietary/lifestyle factors may also play a role in determining resilience or susceptibility to severe outcomes after SARS-CoV-2 infection. High fat diet has previously been shown to increase ACE2 mRNA expression in adipose tissue as well as the kidney and liver [6]. Furthermore, a recent meta-analysis found that diabetes was associated with more severe outcomes in COVID-19 patients [7]. These findings might also suggest that racial and ethnic differences in rates of metabolic/cardiovascular disorders could contribute to gene $\times$ environment interactions in determining COVID-19 susceptibility.

Interestingly, nicotine has been shown to decrease the expression of ACE2 in neurons and glia [8]. While the damage to lung tissue caused by smoking would likely exacerbate COVID-19 pathology, nicotine consumption by other methods (i.e. oral lozenge or transdermal patch) could potentially confer some resilience against neurological complications. The ACE inhibitors and angiotensin II type-I receptor blockers (ABRs) losartan and olmesartan have been found to significantly increase ACE2 expression in humans and animal models [9]. Ibuprofen, a frequently administered non-steroidal anti-inflammatory drug (NSAID), has also been shown to increase ACE2 [10]. The upregulation of ACE2 by drugs such as ibuprofen alone or in combination with ARBs or ACE inhibitors may thus exacerbate SARS-CoV-2 infection. In fact, preliminary reports from physicians in France have indicated that administration of NSAIDs was associated with more severe outcomes in patients infected with SARS-CoV-2.

Thus, it is possible that multiple independent variables may affect ACE2 expression and thereby confer resilience or susceptibility towards severe life-threatening conditions after SARS-Cov-2 infection. A crucial step forward in understanding disease variability in COVID-19 patients will be the cross-referencing of patient medical history (prescription drug use) with blood glucose levels, air pollution index in city of origin, history of nicotine consumption, and 


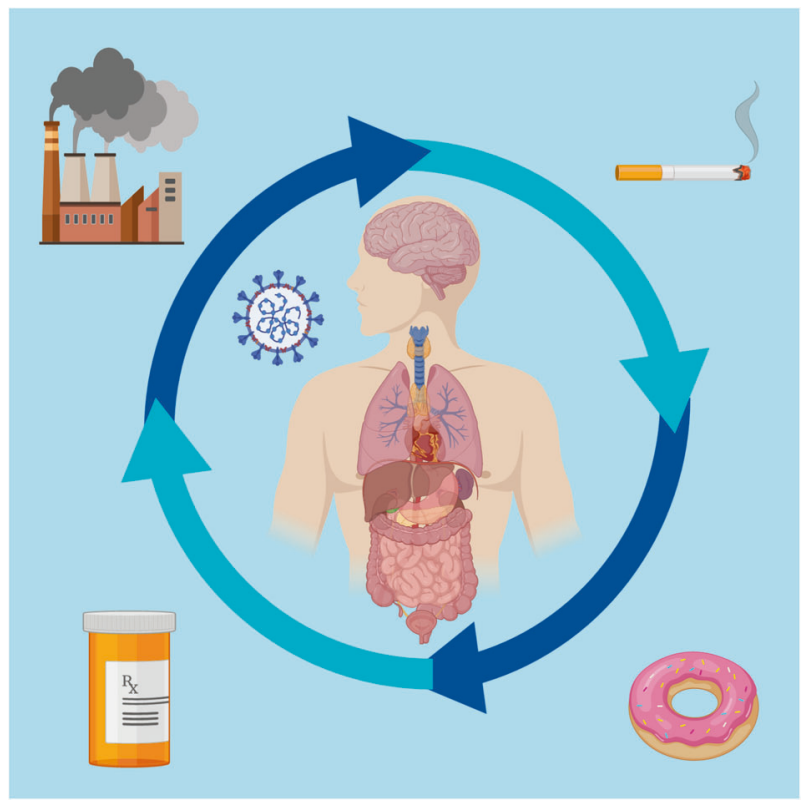

Fig. 1 Environmental and lifestyle factors and SARS-CoV-2 susceptibility. ACE2 is readily distributed throughout a number of organs as well as the nasal mucosa and can be modulated by pharmacological, toxicological, and dietary factors.

any additional variables which are found to affect ACE2 expression.

Acknowledgements This study was supported by Grant Number P50 AT008661-01 from the NCCIH and the ODS. Dr. Pasinetti holds a Senior VA Career Scientist Award. We acknowledge that the contents of this study do not represent the views of the NCCIH, the ODS, the NIH, the U.S. Department of Veterans Affairs, or the United States Government. Figure was made using Biorender.com.

\section{Compliance with ethical standards}

Conflict of interest The authors declare that they have no conflict of interest.
Publisher's note Springer Nature remains neutral with regard to jurisdictional claims in published maps and institutional affiliations.

\section{References}

1. Wan Y, Shang J, Graham R, Baric RS, Li F. Receptor recognition by the novel coronavirus from wuhan: an analysis based on decade-long structural studies of SARS coronavirus. J Virol. 2020;94:e00127-20.

2. Santos RA, Simoes e Silva AC, Maric C, Silva DM, Machado RP, de Buhr I, et al. Angiotensin-(1-7) is an endogenous ligand for the $G$ protein-coupled receptor Mas. Proc Natl Acad Sci USA. 2003;100:8258-63.

3. Li YC, Bai WZ, Hashikawa T. The neuroinvasive potential of SARS-CoV2 may play a role in the respiratory failure of COVID19 patients. J Med Virol. 2020;92:552-5.

4. Lin CI, Tsai CH, Sun YL, Hsieh WY, Lin YC, Chen CY, et al. Instillation of particulate matter 2.5 induced acute lung injury and attenuated the injury recovery in ACE2 knockout mice. Int J Biol Sci. 2018;14:253-65.

5. Conticini E, Frediani B, Caro D. Can atmospheric pollution be considered a co-factor in extremely high level of SARS-CoV-2 lethality in Northern Italy? Environ Pollut. 2020. https://doi.org/ 10.1016/j.envpol.2020.114465.

6. Gupte M, Boustany-Kari CM, Bharadwaj K, Police S, Thatcher S, Gong MC, et al. ACE2 is expressed in mouse adipocytes and regulated by a high-fat diet. Am J Physiol Regul Integr Comp Physiol. 2008;295:R781-8.

7. Fadini GP, Morieri ML, Longato E, Avogaro A. Prevalence and impact of diabetes among people infected with SARS-CoV-2. J Endocrinol Investig. 2020. https://doi.org/10.1007/s40618-02001236-2.

8. Ferrari MF, Raizada MK, Fior-Chadi DR. Nicotine modulates the renin-angiotensin system of cultured neurons and glial cells from cardiovascular brain areas of Wistar Kyoto and spontaneously hypertensive rats. J Mol Neurosci. 2007; 33:284-93.

9. Gurwitz D. Angiotensin receptor blockers as tentative SARSCoV-2 therapeutics. Drug Dev Res. 2020. https://doi.org/10.1002/ ddr.21656.

10. Qiao W, Wang C, Chen B, Zhang F, Liu Y, Lu Q, et al. Ibuprofen attenuates cardiac fibrosis in streptozotocin-induced diabetic rats. Cardiology. 2015;131:97-106. 